\title{
ERNST MACH AND THE EPISODE OF THE MONOCULAR DEPTH SENSATIONS
}

ERIK C. BANKS

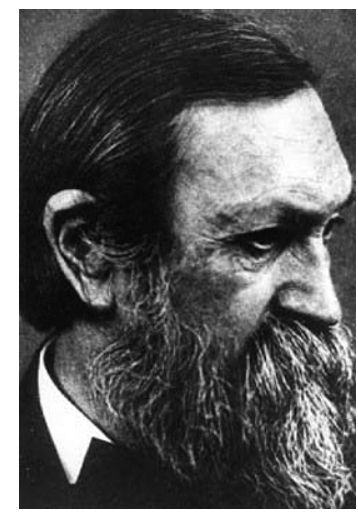

\begin{abstract}
Although Ernst Mach is widely recognized in psychology for his discovery of the effects of lateral inhibition in the retina ("Mach Bands"), his contributions to the theory of depth perception are not as well known. Mach proposed that steady luminance gradients triggered sensations of depth. He also expanded on Ewald Hering's hypothesis of "monocular depth sensations," arguing that they were subject to the same principle of lateral inhibition as light sensations were. Even after Hermann von Helmholtz's attack on Hering in 1866, Mach continued to develop theories involving the monocular depth sensations, proposing an explanation of perspective drawings in which the mutually inhibiting depth sensations scaled to a mean depth. Mach also contemplated a theory of stereopsis in which monocular depth perception played the primary role. (C) 2001 John Wiley \& Sons, Inc.
\end{abstract}

The Austrian physicist, philosopher, and psychologist Ernst Mach (1838-1916) is well known in the history of psychology for his discovery of the effects of lateral inhibition in the retina (the "Mach Bands"). He also engaged in the great controversies of his time, in particular the philosophical conflict of the 1860s over visual depth perception between the empiricists (represented by Hermann von Helmholtz) and the nativists (represented by Ewald Hering). Mach's articles and unpublished notebooks, which are now collected at the Deutsches Museum in Munich, contain indications beginning in the 1860s of his own unique but littleknown theory of monocular depth perception, closely tied to his explanation of the Mach Bands.

Mach held two distinct theories of spatial properties. In physics, he believed they were a sign of deeper relationships of measure (Mach, 1866, p. 232). But in psychology, Mach believed that spatial length, width, and depth were actual sensations like color, smell, or taste (Mach, 1886/1959, p. 8). Psychologically, spatial representation seemed to him innate and biological in nature and thus inseparable from human sense experience. Yet this very fact called urgently for an "antimetaphysical" elimination of the physiological properties of space

ERIK C. BANKS received his Ph.D. in 2000 from the City University of New York for his thesis "Ernst Mach's World Elements," based on his study of Mach's Nachlass during the summer of 1999. His e-mail address is erikb2000@netzero.net. 
from physical thought. As part of his overall antimetaphysical program, Mach was motivated to explain the emergence of space perception as a biological phenomenon.

\section{MACH's SPACE SENSATIONS}

Even in psychology, Mach identified numerous separate mechanisms within the body for spatial representation. These included tactile and retinal local signs (Localzeichen), sensations of equilibrium controlling the involuntary eye movements, ${ }^{1}$ and an innate apparatus of kinesthetic muscular sensations present at birth. The sum total of the local bodily sensations, Mach said, formed a "fixed register" into which the experiences of the world were entered like numbers into a blank account book (Mach, 1905/1960, p. 17).

Mach held that certain space sensations in the eye, particularly the monocular and binocular sensations of depth, were engendered by the local signs of the retina. Localzeichen were the brainchild of Hermann Lotze, who regarded them as simple feelings of place that combined with one another in sequence, leading to the complex sensation of extended spaces. Herbart, Lotze, and Wundt all pioneered sophisticated psychological constructions of space from space-less, intensive elements, which influenced Mach ${ }^{2}$ significantly in his physics.

Those who regarded space as a construction of elements became known as "empiricists," the most pronounced example of whom was Wundt, who wrote that "the spatial order is developed from the combination of certain sensational components which, taken separately, have no spatial attributes" (Wundt, 1897, p. 127). Those who regarded the spatial system of vision as more or less fixed at birth were known as nativists. In the theory of vision, Mach followed Ewald Hering's nativist theory of stereopsis, which employed local signs for depth on both retinas. Indeed, from reading Mach's Analysis of Sensations one would never guess that there was any theory other than Hering's.

What is not generally known is that Mach used his own research on the Mach Bands to enhance and fill out Hering's theory. In particular Mach was interested in monocular impressions of depth induced by illuminated surfaces and perspective drawings. Based on these studies, he concluded that local sensations of length and depth were not fixed properties but more like light sensations, mutually inhibiting one another, bending, distorting and scaling to an average value. Mach even said that the depth sensations followed a law of the "reciprocal action of retinal points" similar to the law he had discovered for light sensations (Mach, 1868, p. 734). ${ }^{3}$ Mach's investigations during the 1860 s on the relationship between the bands and the monocular depth sensations are a lost episode in the history of psychology, which showed just how willing he was willing to consider space a sensation like light or color.

1. These include a series of rolling motions of the eyes to compensate for the tilting of the head. If one tilts one's head $45^{\circ}$ to the side, both eyeballs roll in the opposite direction keeping retinal images fixed in place and leading to the impression of a fixed world attaching to those images. Another motion is the familiar one of watching a train car pass, where the eyes follow the train and fix it in place, then snap back to the next car and follow it, without an apparent break in the continuity of the impression. As Mach showed in his famous work on sensations of movement (1886/1959, Chapter 7), these eye motions can also be brought about in a person blindfolded and sealed in a dark spinning box, with no indications of movement cues besides linear and angular accelerations.

2. Herbart's reproduction series, Lotze's local-signs, and Wundt's complex local-sign theory are all reviewed in Mach's early work, "Vorträge über Psychophysik" (Mach, 1863a).

3. Mach, 1868, p. 734: "Es scheint mir für die Gestaltempfindung ein ganz ähnliches Gesetz der Wechselwirkung der Netzhautstellen zu herrschen, wie jenes, welches ich für die Lichtempfindung constatirt habe." ("It appears to me that for the sensation of form, a completely similar law of reciprocal action of retinal points holds to that which I have framed for light sensations.") 

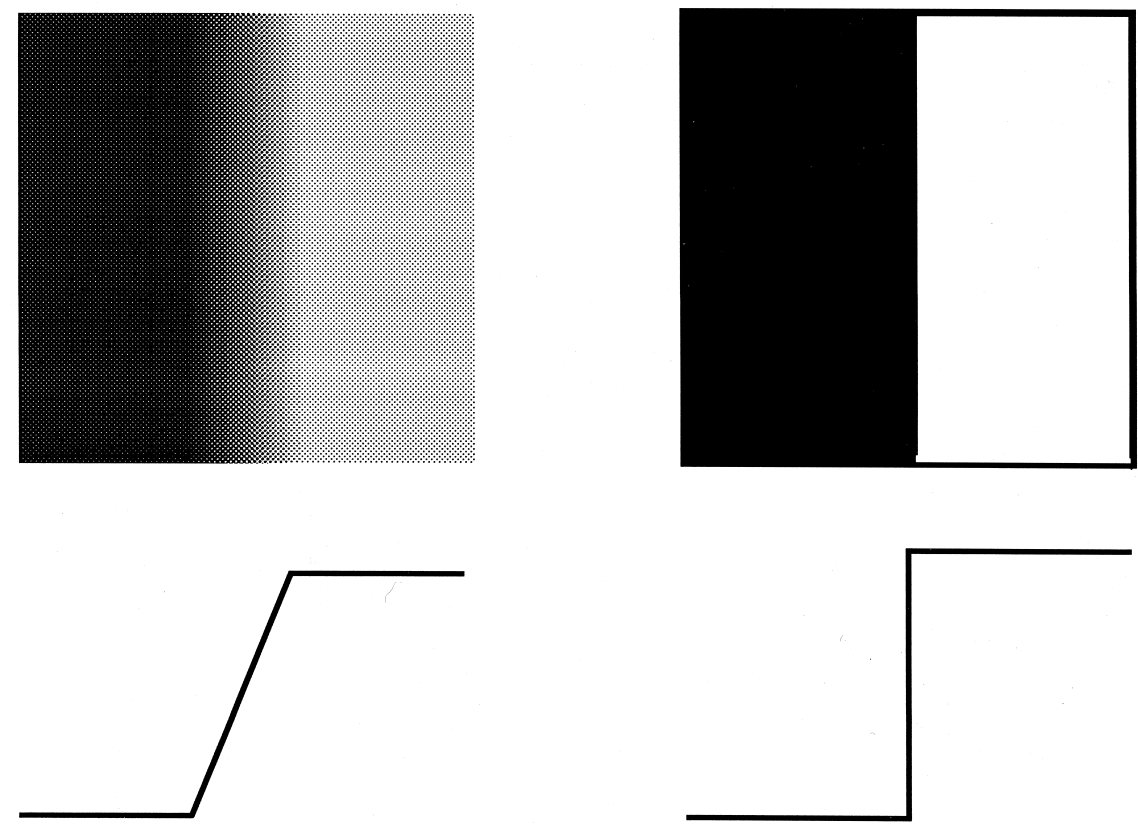

FIGURE 1.

Trapezoidal- and square-shaped luminance distributions.

\section{MACH BANDS AND LATERAL INHIBITION}

Mach's most important psychophysical researches in his Graz and early Prague period (1864-1868) centered on what are now called Mach Bands. Good examples of these subjective phenomena are afforded by trapezoidal-ramped luminance distributions (Figure 1, left). Following from left to right, a black plateau suddenly increases through a penumbra of gradually lighter grays to a white plateau on the right. Subjectively, a dark band should appear just after the ramp turns upward and a light band just after the ramp turns downward. Mach pointed out that the dark and light bands were not properties of the objective illuminance distribution. Interestingly, it is not just sudden changes from light to dark that produce the bands, since they disappear in illuminance distributions featuring sharper edges, such as an edge of pure black against pure white (as in Figure 1, right) (Morrone, Ross, Burr, \& Owens, 1986).

Even in his first paper, Mach offered an explanation that has since become standard (Ratliff, 1966, pp. 267-271). He knew from the retinal anatomy of his time that the light receptors did not plug directly into the optic nerve. Instead the receptors were cross-connected with one another first, so that one optic nerve fiber culled the responses of about 100 individual receptors. To Mach, this meant that each receptor responded to two sources of incoming information. The first source was the actual brightness of the light shining on it. The second source came from the responses of neighboring receptors, which contributed by inhibiting the first. Thus, Mach hypothesized, the response a given receptor passed on to the optic nerve and the higher visual system was really something like an average worked out from the mutual inhibition of the receptors. He wrote that the receptors must undergo "a series of reciprocal 
actions" (now called lateral inhibition) before their excitations were transmitted to the optic nerve (Ratliff, 1966, pp. 268-269).

It followed from Mach's anatomical considerations that the actual brightness of a lighted point on the retina was different from its sensed brightness. Because lateral inhibition acted to level off differences in brightness between one point and another, only extreme contrasts survived the processing. A point appeared brighter when it was above the average brightness of its neighbors and darker when it was below the average of its neighbors. Looking back in 1906 on his earlier work, Mach expressed the principle as follows:

The illumination of a retinal point will, in proportion to the difference between this illumination and the average illumination on neighboring points, appear brighter or darker respectively, depending on whether the illumination of it is above or below that average. (Ratliff, 1966, pp. 321-322)

The absolute illuminance made a difference, of course. The difference was noticed between a room lit by candle light and one lit by sunlight, but any contrasts were greatly exaggerated. Mach remarked: "The visual organ shows a definite unmistakable tendency to schematize, in that it merely notices striking irregularities. The same tendency manifests itself in details as well as the whole field" (Ratliff, 1966, p. 265). He went on to say that the whole retina scaled its impressions of brightness from the middle tone of the visual field. Photographers also do this when they meter for the middle tone of a picture and not the absolute brightness, allowing absolute grays to overexpose to whites and dark tones to underexpose to black, so that the maximum detail of the image is attained. The evolutionary advantage of such an optic system is that an animal's perception of contour and shape remains unaffected by the level of ambient light.

Without a detailed map of the various discrete receptors and their interconnections, the actual law of inhibition could not be stated (as would later be true of the law for depth sensations). However, Mach could offer a convincing sketch of what was going on in his experiments with illuminance (see Figure 2). Along the steady plateaus, and along each section within the ramp, every light sensation was the average of its neighbors. Figure 2, top, shows an imaginary group of receptors placed along different points on the curve. Within the ramp and on the plateaus, no stark contrasts are sensed and the impression, Mach claimed, was that of a more or less uniform area. At the points where the ramp begins (M) and ends $(\mathrm{N})$, the middle point is respectively darker and brighter than the average, which lies on the straight line. This difference will then be reflected in the perceived brightness of those points by a spiking downward at $\mathrm{M}$ and upward at $\mathrm{N}$ (Figure 2, bottom).

Mach was aware of the anatomical similarity of neural tissue in the retina to brain tissue, and he quickly extended his analysis of the retina to cognition in the brain by asking, "why should the ganglion cells of these organs behave differently than those of the rest of the nervous system and the brain?" (Ratliff, 1966, p. 269). In an 1863 article, in which he attempted to vindicate Herbart's theory of inhibition of ideas by each other, Mach guessed that reciprocal inhibitions existed in brain tissue:

It appears to me very plausible that generally speaking attention has its grounds in the mechanism of the body. If nerve energy is liberated in certain paths, then through this very mechanism other paths are cut off. And what is valid for sensory sensations might be valid for thought also. Thought can be conceived as a change of attention. Certain physical processes therefore exclude others. In the measure to which the first occur, the others withdraw. Physical processes, sensations, press against one another. We have 


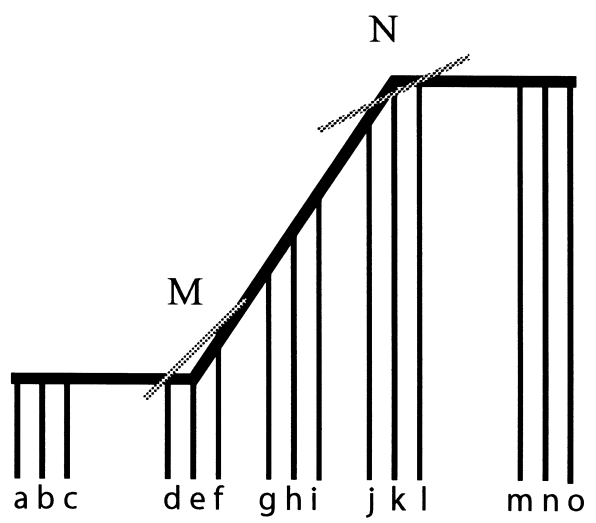

a. Activation of Receptors

\section{b. Perceived} Brightness

FIGURE 2.

Explanation of Mach Bands and perceived brightness.

found on physiological grounds a law that governs the sensations similar to that which Herbart long ago expressed for the ideas. (Mach, 1863b, p. 297)

And, contrariwise, for Mach, the eye's neural tissue was capable of rudimentary "thinking processes"; there was no need at all to refer all processing to so-called unconscious inferences (Unbewusster Schluss) as Helmholtz and Wundt had sometimes done. Helmholtz especially had maintained in the third volume of his monumental Handbook of Physiological Optics $(1866 / 1962)$ that many sensory phenomena and illusions were due to inductive inferences by the central nervous system, whereby an ambiguous present experience was interpreted with the help of memories of previous occasions, and not by any innate organization of the sense organs. Mach took exception to this:

I now have grounds to believe that the majority of the phenomena which we have believed to be errors of judgment (i.e., essentially due to processes in the central nervous system) actually have their basis in a more autonomous behavior of the sense organs. I will describe a series of observations that led me to the view that is already becoming familiar in comparative anatomy, namely that the sense organs are to be considered as subordinate central organs. (Ratliff, 1966, p. 308)

4. "This phenomenon of contrast is not restricted to the sense organs. It is even more prominent as a general characteristic of the neural pathways, in the blocking of weak excitation by the nerves that are carrying stimulation. A similar mechanism of the nervous system accounts for the fact that a person is unable to think of two different things at the same time." 
More recently, Georg von Békésy (1960, p. 538) and Floyd Ratliff (1970) firmly upheld Mach's extension of neural inhibition in the eye to central processes, as did neurophysiologist R. Jung at the 1966 Freiburg Mach Symposium:

The visual phenomena discovered by Mach are not only sensory mechanisms for the improvement of the perception of contrasts, but rather also general principles of distribution for excitation and inhibition: every stronger excitation in the central nervous system is surrounded by a wall of inhibition. This hinders unbounded widening of the excitation, which would otherwise lead to massive neural discharge and to epileptic seizures. The physiological bounding of excitation works with contrast mechanisms toward raising to prominence significant patterns of excitation [Erregungsmuster] and at the same time serves a functional ordering which keeps the entire nervous system at a mean level of excitation. Mach had already expressed similar thoughts in his economy principle. (quoted in Kerkhof, 1966, p. 135)

Von Békésy rediscovered Mach's work in 1928, attributing a neurological law of contrasts to him and applying it to the nerve endings of the cochlea in the inner ear. The stimulus produced in the cochlea by traveling pressure waves, which were first demonstrated by von Békésy, was far too diffuse to explain sharply localized sensations of tone, unless there was a mechanism for focusing the stimulus:

It appears that Mach's law of contrast should play a highly significant role in auditory theory. It achieves a certain patterning of sensation. A distribution of stimulation in the form of a single resonance curve will produce a high peaking of the maximum because at this point the stimulus intensity undergoes its greatest variation, whereas on either side the stimulus effect falls off and the curve there is convex downward. (von Békésy, 1960, p. 418)

Von Békésy also produced an article for the Freiburg Symposium entitled "Die Erweiterung der Existenz der Mach-Bänder auf andere Sinnesgebiete" (The Extension of the Existence of Mach Bands to Other Senses) in which he showed that the skin and even the taste buds exhibited the phenomenon (Kerkhof, 1966, pp. 161-169).

\section{Mach BAnds And Monocular DePth Sensation}

Mach made a special series of remarks about the ramp-like illuminance distribution that increases steadily according to the law of a straight line, such as the penumbra of grays in Figure 1 . Here there were no above-average brightnesses but only a steady change from dark to light. Clearly when we look at a gradient in ordinary surroundings we notice a change from one side to the other. Mach's inhibition theory implied, however, that when the entire field of vision was taken up with such a distribution, the gradient of brightnesses should have been sensed as uniform gray, since there were no above average contrasts.

Mach did such an experiment by fixing a cylindrical surface in a box and looking at it through a hole with one eye. According to the laws of illumination, a cylindrical surface produces a steady brightness gradient. Along the cylindrical wall in the box, however, Mach remarked that he did not notice a rise in illumination, but experienced instead the sensation of a uniformly bright surface in depth (Ratliff, 1966, pp. 264, 288-289). Lighting differences had given way to depth. Depending on what direction the light was seen to come from, the surface of the cylinder was sensed as a bump or a hollow. Again, Mach rejected the idea, which naturally suggested itself, that such a connection between light and depth sensations was the result of previous experience and memory. An unconscious inference, as hypothesized by Helmholtz, might run: whenever I have seen light surfaces like this before, they were on 
the uniformly lighted surfaces of bumps or hollows, therefore this must be such a case. Mach sought instead a biological mechanism for connecting light and depth sensations like the parts of a machine.

Mach's sallies against Helmholtz's mode of explanation showed that he was aligning himself with the nativism of Ewald Hering (Ratliff, 1966, p. 298) on the issue of how depth was perceived. This is not the place for a history of the philosophical clash in Germany between the nativist and empiricist schools, both of which could claim a lineage from the transcendental idealism of Kant. ${ }^{5}$ Suffice it to say that the psychological problem came to a head in the mid-1860s when Hering published a comprehensive nativist theory of stereopsis in which he claimed depth was sensed by means of an innate organization of the two retinas, and was not inferred from experience. Hering modeled his theory of innate depth perception on Johannes Müller's theory of corresponding points. ${ }^{6}$ Müller had started from the anatomical fact that nerves from the visual field crossed over one another at the optic chiasma on their way to the brain, connecting up the left retina's temporal half with the right retina's nasal half and vice versa. The points that were joined were said to be corresponding.

Müller drew the set of all corresponding points from both eyes as a circle passing through the point on which the two eyes were fixed and the optical centers of both eyes (see Figure 3 ). He hypothesized that this set of points, called the horopter, would be seen as single and fused in depth. The other images along noncorresponding points would be seen double. However, no sooner was his theory out than Müller was contradicted by the physicist Wheatstone, who had invented the stereoscope, and who claimed that points not on the horopter could also be seen as fused and in depth. There was, in fact, a whole area of fused images surrounding the horopter, later called Panum's fusional area. For Wheatstone, what counted was the similarity in the form of images on the two retinas and not whether the points corresponded or did not.

Wheatstone's work revived an older theory of projection, which claimed that the mind received two retinal surfaces, somehow recognized the objects in them as similar, and calculated from their retinal disparity, the distance between the two eyes and their angle of convergence, the depth at which a single object would have to be situated in order to cast the two images. These inferences were presumed to be unconscious and automatic; the observer saw not the two flattened retinal surfaces before the mind but a fused field in space external to his eyes. Helmholtz seems to have inclined toward a form of the empiricist projection theory, but also endorsed nativism for some elements of vision.

Hering's theory of stereopsis, which appeared in Part Five of his Beiträge zur Physiologie in 1865 (Hering, 1865), revived Müller's theory once again. As R. Steven Turner writes:

Hering found it inherently implausible that the eye's mind should be constantly recalculating the distance of external objects and projecting their images appropriately. $\mathrm{He}$ charged that projection theories merely reify the geometrical abstractions of the physicist and substitute them for real subjective perceptions and their underlying physiological mechanisms. This criticism encapsulated his lifelong hostility to explanations that por-

\footnotetext{
5. The influence of the philosophical debate on the development of psychology is covered in Boring 1944 and 1950. Helmholtz, in his Handbuch (Vol. 3), related his view of the conflict, and may have been responsible for the formulation Empiricismus und Nativismus as opposed to the usual "Empiricism and Rationalism"- - the two divisions are not coextensive; Nietzsche, for example, was a nativist but hardly a rationalist. James' Psychology, Lotze's Logik, Wundt's Logik, and Mach's Erkenntnis und Irrtum are good sources for those investigating the intersection of the philosophical debate with nineteenth-century psychology.

6. My treatment of the development from Müller to Hering and Helmholtz derives from Boring (1944) and Turner (1994).
} 


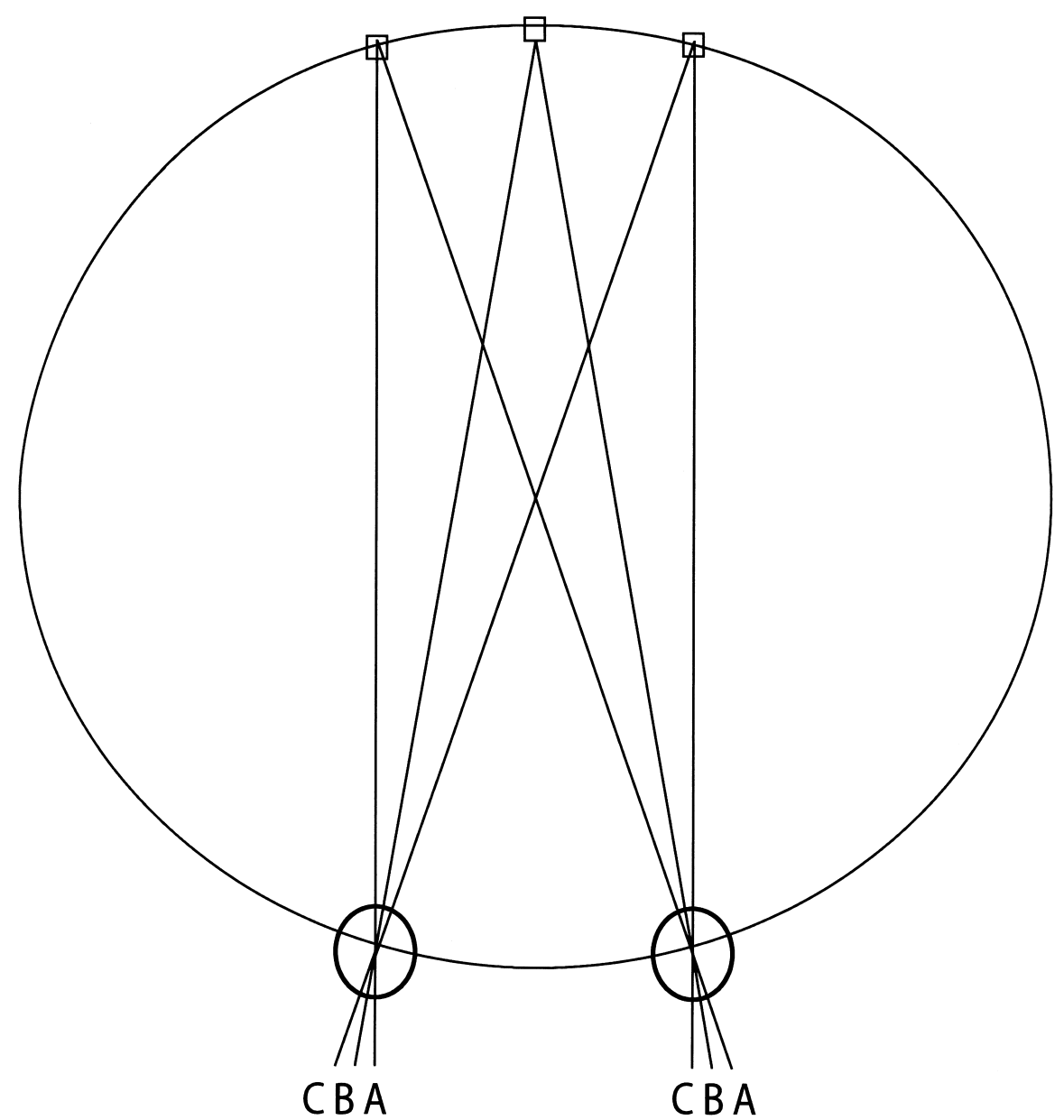

FIGURE 3.

Müller's horopter.

trayed the processes of sensory perception as analogous to higher intellectualistic functions of the mind, rather than as immediate expressions of the life forces in the sense organs themselves (Turner, 1994, pp. 61-62).

Hering regarded the connections of the corresponding points as mutually inhibiting, like numbers with + and - signs. For Hering, points connected up to the same nerves averagedout one another when they were fused into a binocular perception. To show how the process of inhibition worked, Hering demonstrated that the direction of sight for both eyes was an "average" of the lines of sight from each individual eye. He proved this by an elegant experiment. Sit down in front of a window with your left eye shut and the right eye fixed on a distant object, such as a flagpole. Mark the spot on the window with an X. Now close your right eye and open your left and note the object your left eye sees through the X. Say it is a tree. Now open both eyes and stare through the X. Surprisingly both the flagpole and the tree are seen in the same straight line through the X. Thus, objects lie in the 

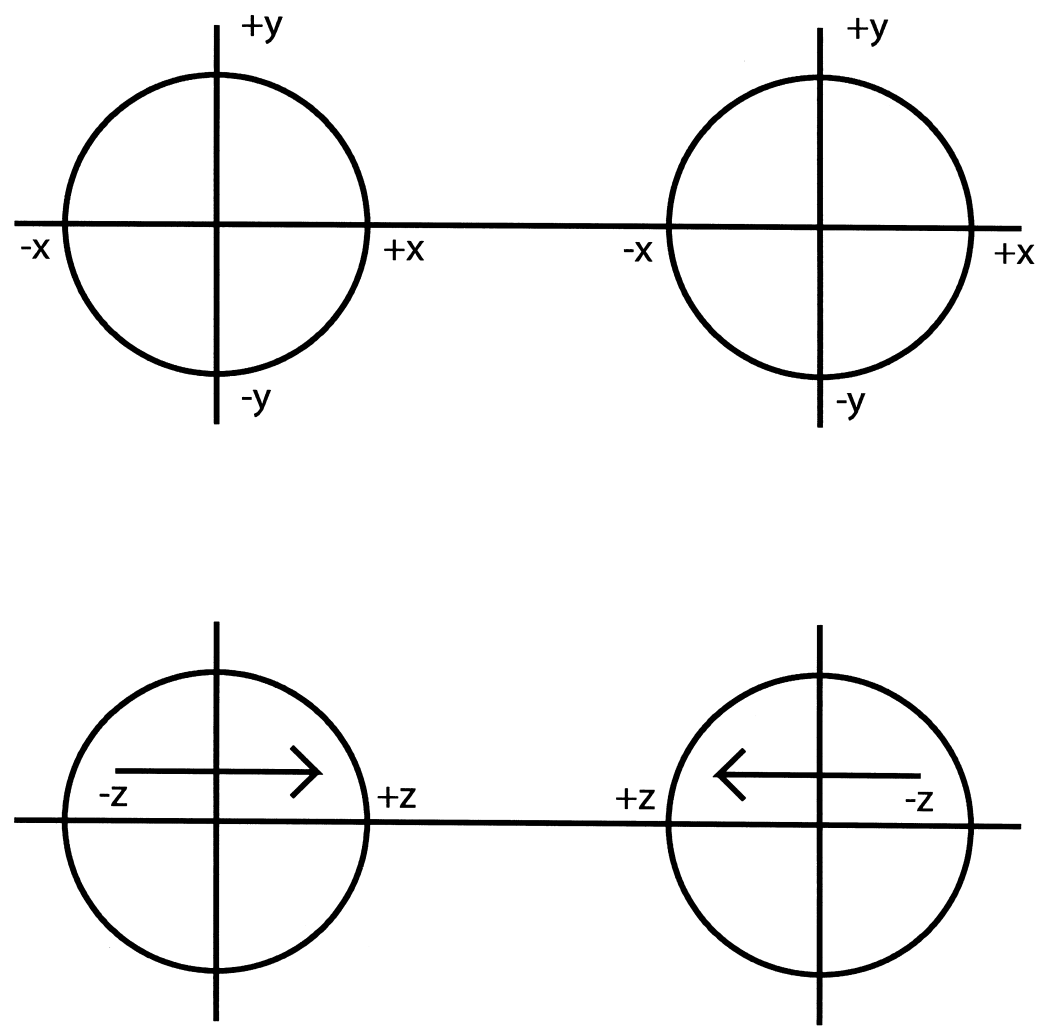

FIGURE 4

Hering's width (x), height (x), and depth (z) local signs.

same visual direction for the fused "cyclopean" visual field that are in opposite directions for each eye.

Hering explained these facts of visual perception with the scheme in Figure 4, top. Each eye was to be divided into $\mathrm{x}$ and $\mathrm{y}$ axes, with the fovea at the origin. These conventions yielded a set of height and width sensations with positive and negative sign. Hering said that whenever one eye was used, the position of the object was immediately sensed on this grid of local signs. When both eyes were used, the direction in the fused image was the sum of the $\mathrm{x}$ and $\mathrm{y}$ values with signs taken into account. Images on corresponding points were equal in value and opposite in sign and were thus seen in the same direction dead-on (Mach, 1886/ 1959 , p. 124). Other points not undergoing inhibition at all were seen double. In fact, as Helmholtz also remarked, the visual field was filled with double images that go unnoticed.

To explain binocular depth perception, Hering postulated a set of depth signs on the retina. Depth values (z) were arranged on each eye to increase in value from the nasal side of the retina to the temporal side, and were opposite in sign on either side of a meridian drawn down the middle (Figure 4, bottom) (Mach, 1886/1959, p. 124). Objects on corresponding points had equal and opposite depth values and were seen on a mean zero-depth surface that Hering called the Kernfläche, roughly translatable as the "base-line surface" (pictured in Figure 5). This was the surface previously called the horopter, although Hering 


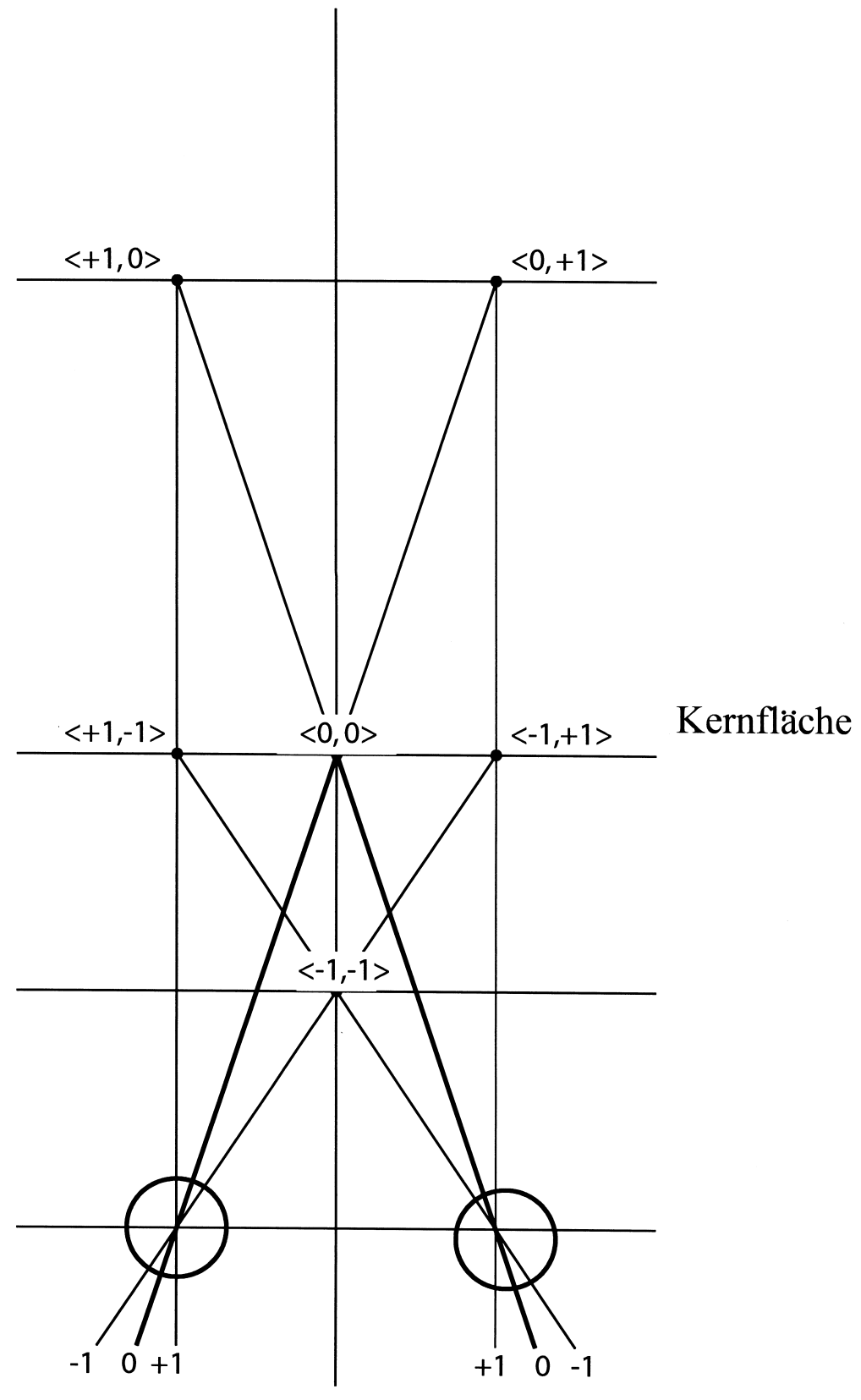

FIGURE 5.

Hering's binocular scheme of local signs for depth.

determined its shape more precisely. Objects were seen at positive or negative depth, figured always from the zero position of the baseline. Hering showed that all points on the somewhat elliptical horopter were seen in binocular vision as if they lay on a flat wall.

The theory (as pictured in Figure 5) was simple and elegant, using only two signs, + 
and - . Hering even accounted for double images on noncorresponding points, giving them each a separate depth value, but no average since they did not inhibit and fuse. In 1866, Mach declared himself in print to be a follower of Hering (Ratliff, 1966, p. 298), even after the appearance of Helmholtz's significant attack in the Handbook, which ushered in a new crisis in the theory of vision.

\section{HelmholtZ's CRitique of THE Monocular DePTH SENSATIONS}

Helmholtz's most trenchant criticism targeted Hering's monocular depth sensations. He reasoned that if Hering were right and local depth signs were spread out along the retinas from right to left, then covering one eye, or even parts of one eye, would still leave only some monocular depth sensations active. This would mean, for example, that if the observer covered one eye and faced a horizontal flat wall, then, because the other eye's monocular depth sensations no longer inhibited the first's, the whole wall should be seen angled toward the observer. Specifically, points falling on the nasal side of the eye should have been seen as having greater depth than the points on the temporal side. Needless to say, experience did not confirm this conjecture, nor any of the sequence of variations Helmholtz proposed. ${ }^{7}$

Hering had been forced by other evidence as well to admit that certain experiential cues could override the monocular depth sensations and, in his Lehre vom binocularen Sehen (1868/1977), he claimed only that similar overall forms of objects would be fused in stereopsis, not point-to-point matchings. This seems to have been a concession to the projection theory. Turner relates that there were additional problems for Hering concerning the relearning of stereopsis by people with improperly aligned eyes, which would have been impossible if the corresponding points had to be precisely connected (Turner, 1994, pp. $168-$ 169). Turner writes that, due to these attacks, as of 1866 the monocular depth sensations had become a dead issue: "Neither [Hering] nor any of his students ever again defended the hypothesis of monocular depth-values following Helmholtz's attack of 1866" (p. 86).

This assertion, however, overlooks the Mach Band articles, namely Mach's 1868 article, "Beobachtungen über Monoculare Stereoscopie," and the Analyse der Empfindungen (published in 1886), in which he attempted to save the monocular depth sensations for Hering. Indeed in the Mach Band articles, Mach turned immediately from his study of light sensations to consider steady gradients and their ability to induce monocular sensations of depth. Mach also ventured hypotheses about depth sensations and perspective drawings in which he extended his principle of neural inhibition to depth signs. A contemporary simply could not have read Mach's articles of the 1860s without thinking of the Hering-Helmholtz controversy, and the Mach Band papers are accordingly peppered with broadsides against Helmholtz and defenses of Hering, as if Mach felt his work was relevant to that debate. The impact of these works seems to have been negligible, however, as even Mach's studies of the Bands were ignored. Summing up those years from the perspective of 1906, he wrote: "My reports have remained almost unknown or unnoticed for a long time, such that indeed the facts concerned were again discovered independently by observers more than 30 years later" (Ratliff, 1966, p. 322).

\section{LIGHT AND DEPTH SENSATIONS}

Mach had hoped to save Hering's theory by arguing first that monocular depth sensations could be activated by light. He then applied his theory of neural inhibition to explain why

7. But see Turner (1994) for some of the ingenious ways Hering's students picked up the challenge. 


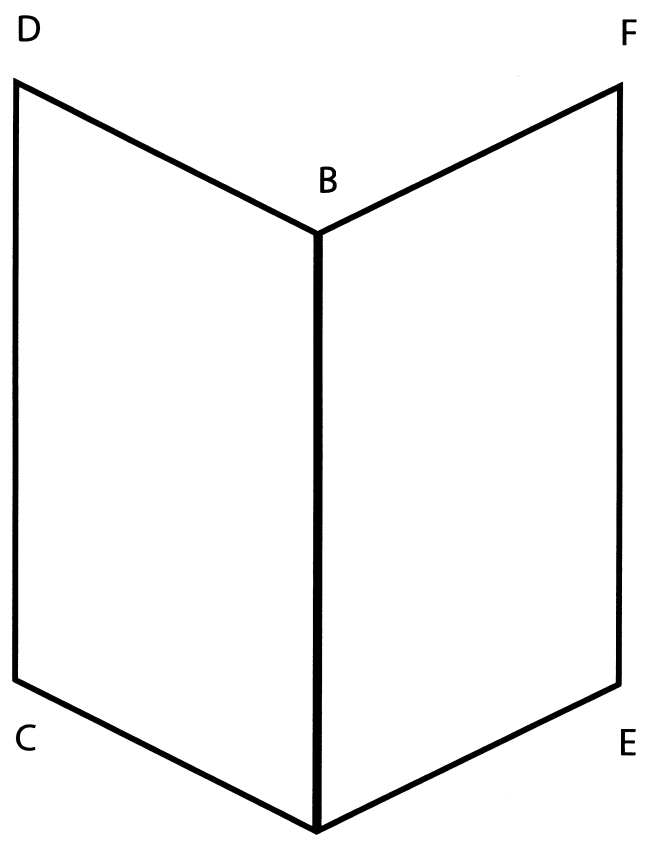

A

FIGURE 6.

Mach card.

steady increases in depth sensation would go unnoticed - the point at issue in Helmholtz's flat-wall objection. This extension of complex neural inhibition over areas to depth sensations was entirely original with Mach.

In the third Mach band article, "Über die physiologische Wirkung räumlich vertheilter Lichtreize, Dritte Abhandlung" (On the physiological effect of spatially distributed light stimuli (third paper); Ratliff, 1966, pp. 285-298), Mach called special attention to the relationship between light and depth sensation, using the phenomenon of the "Mach Card":

If I fold a rectangular piece of stiff paper along a straight line to form two congruent rectangular parts and place it on the table in front of me so that when vertical it has the projecting side turned toward me, I obtain the image shown in [Figure 6]. The light should fall from the left and the right side will thus be somewhat darker. If then I close one eye, the sensation is almost completely unaltered. If I try to see the paper as recessed, however, I succeed after some effort. The left side thereupon appears to become much brighter and the right side much darker. Light and shade appear as if painted upon it. Moreover I notice a different color on the right and left sides which had not been noticeable to me earlier. Furthermore the form of the paper has changed. The lines bf, bd have become longer than ae, ac, the lines cd and ef shorter than ab. Finally the corner ab no longer remains vertical, but the paper lies like an open book before me. These simultaneous alterations of the sensation of depth, the sensation of form and the sensations of light which occur without the slightest theoretical deliberation, indicate how quickly these things, through well-regulated reflexes transform themselves into one another. It thereby appears that the sensation through which another becomes elicited, itself diminishes in the same proportion as it elicits the other. (Ratliff, 1966, pp. 295-296) 
The reader should try this experiment using Figure 6 as a guide. An ordinary piece of white paper and a desk light in a darkened room will do. The result is fascinating; instead of a white paper with shading, one gets the opposite impression of half-white, half-black (or gray) paper bathed in strong light. ${ }^{8}$ As the depth sensations of the paper reverse, light sensations also reverse; as the paper appears closer, it darkens. Finally, the rectangular sections of the paper contract into two trapezoidal-shaped sections. Thus, the Mach Card suggests some kind of rigid, automatic connection among the sensations of light, depth, and length.

Mach thought so very highly of this connection that he compared their relationship to the conservation of energy - when the potential energy decreases the kinetic energy increases and the sum remains constant (Mach, 1886/1959, p. 211). Mach used the postulated invariant relationship among light, depth, and length sensations as a basis for defining objecthood in the visual field:

we may expect that whenever a coherent mass of sensations, which, in virtue of its continuous transitions and its common coloring, merged into a unity, exhibits spatial alteration, the change will be seen preferably as the motion of a solid body. I must confess, however, that this way of looking at the matter does not satisfy me. I believe rather that here too an elementary habit of the organ of sight is at the root of the mattera habit which did not originally arise through the conscious experience of the individual, but on the contrary, antecedently facilitated our apprehension of the movement of solid bodies. If we should assume, for example, that every diminution of the transverse dimension of an optical sensation mass to which the attention was directed had the tendency to induce a corresponding augmentation of the dimension of depth, and vice versa, we should have a process quite analogous to that which we have considered above [The Mach Card demonstration] and which was compared to the Conservation of Energy. This view is certainly much simpler and supplies an equally adequate explanation. Furthermore it allows us to comprehend easily how such an elementary habit could be acquired, how it could find expression in the organism and how the disposition toward it could be inherited. (Mach, 1886/1959, pp. 233-234)

Mach thus believed the solid visual object was like a function in terms of light, depth, and length sensations. For the object to remain the same when any one of these elements changed, another had to offset it. In Mach's example from the citation directly above, as the surface of a sensation-mass was tilted away, and perhaps reduced in illumination, the depth sensation increased and supplied the lack so that the overall impression was of a constant object of uniform color and size, smaller in its retinal image and different in lighting because of the eye's additions of depth.

\section{MACH BANDS AND DEPTH SENSATIONS}

In his third Mach Band article, Mach had shown that a cylinder cast a lighted surface that rose only steadily in its lightness gradient, and was sensed, in depth, as either a bump or a hollow (Ratliff, 1966, pp. 287-288). Bumps and hollows cast identical light surfaces-as can be seen by comparing the identical lighting of a convex plaster cast of a face and the concave mold. Thus, it was also necessary to know the direction of the light to arrive at an unambiguous perception of the relief. Once again rejecting unconscious inference, Mach used his experiment to claim that a cylindrical curve of depth sensations was automatically triggered by light sensations of a steady gradient:

8. When I do this experiment in a darkened room, I allow the shaded side of the paper to be as dark as possible, and, upon inverting get the sensation of black paper. Some of the referees of this essay did not see quite so dramatic an effect, perhaps because of the darkness of the shading or of the room. 
Let us imagine for a moment that every retinal point could generate sensations of depth of different intensity in addition to light sensations of different quality and intensity. It would now require nothing more than a simple reflex mechanism, which would trigger the depth sensations simultaneously with the light sensation, for this phenomenon to be understood. Three successive retinal elements, from right to left, of which the left is always more strongly illuminated than the right, would always generate in themselves three depth sensations, which would increase in the opposite direction, but in such a way that the middle element would produce a somewhat greater depth sensation than the average depth sensation of the two neighboring elements. (Ratliff, 1966, p. 289)

From this remark it would appear that the depth sensations were supposed to be triggered by the light surface itself, not the perceived sensation surface that was flattened out by the lateral inhibition of the light receptors. Adding some quantitative detail to his theory, Mach wrote in his Notebook of 1904:

Theory of plasticity and illumination. A constant increase of light corresponds to a constant curvature of the surface. The depth sensation integrates the light intensity.

Light intensity - rise, fall in depth

Rise in intensity - curvature of the surface. ${ }^{9}$

He meant that a surface of constantly increasing illumination, following the law of a straight line, was assigned a curve of depth values. He also said that the curve of depth sensations was the "integral" of a straight-line increase in lighting. Taken literally (as in Figure 7A) this would mean that an illuminance gradient $i(x)=k x+b$ would integrate to a depth curve, $\left.z(i(x))=\frac{1}{2} k x^{2}+C\right)$. Of course the observer does not see a parabolically curved surface, but a cylinder, so this increase in depth must then have been subject to further inhibition processing among the depth elements which flattened the curve out (Figure 7B).

Further, as Mach put it by saying "light intensity — rise, fall in depth," the integral law predicted that a constant illumination would trigger a straight-line increase in depth sensations on the retina (Figure 7C). The depth sensations would then increase from right to left or left to right depending on the direction of the light. Prima facie, such a case presented much the same problem as Helmholtz's wall, for the predicted inclines in depth were not observed. However, for Mach, monocular depth sensations were subject to further inhibition flattening off the differences (Figure 7D). In the example of the wall, steadily increasing depth sensations would be ignored, since none exceeded the average value of its neighbors, and thus the wall would indeed be sensed as flat. This result, though it was not stated this way, was more than implied by the direction of Mach's thinking, and possibly would have formed the kernel of a defense of Hering against Helmholtz. I cannot imagine that this application could have escaped him; it was more likely the raison d'être of his own theory to begin with. Mach's inhibition mechanism also had an advantage over Hering's, since it was spread over areas and not as dependent on values at individual retinal points.

Mach and Hering were colleagues in Prague for many years and, in all likelihood, they must have discussed the question of the monocular depth sensations at least once. Why, then, did Hering not include Mach's ideas on neural inhibition as part of his own theory? Did he disagree with them or just ignore them? This is just one question that a study of the MachHering relationship should clarify.

9. "Theorie d. Plastik und Beleuchtung. Einer Constanten Steigung d. Lichtes entspricht eine Constante Krümmung der Fläche. Die Tiefempfindung integriert die Lichtintensität. Lichtintensität . . . Stei. Gefäll in d. Tiefe. Steig. d. Intens. - . Krümmung in d. Tiefe.” Notebook dated 8 June 1904 (Ernst Mach Nachlass, Deutsches Museum, Munich, Signatur: NL 174/2/47). 


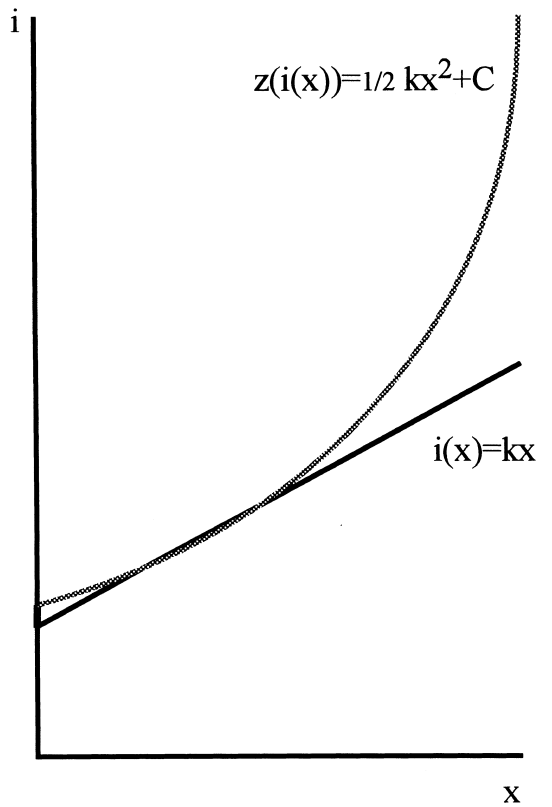

A

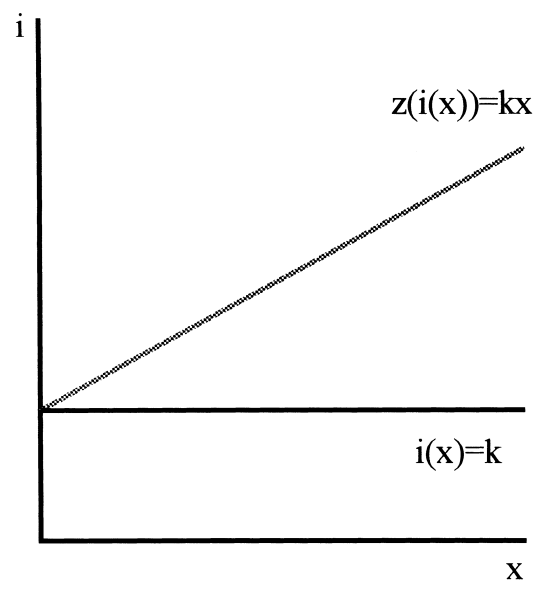

$\mathrm{C}$

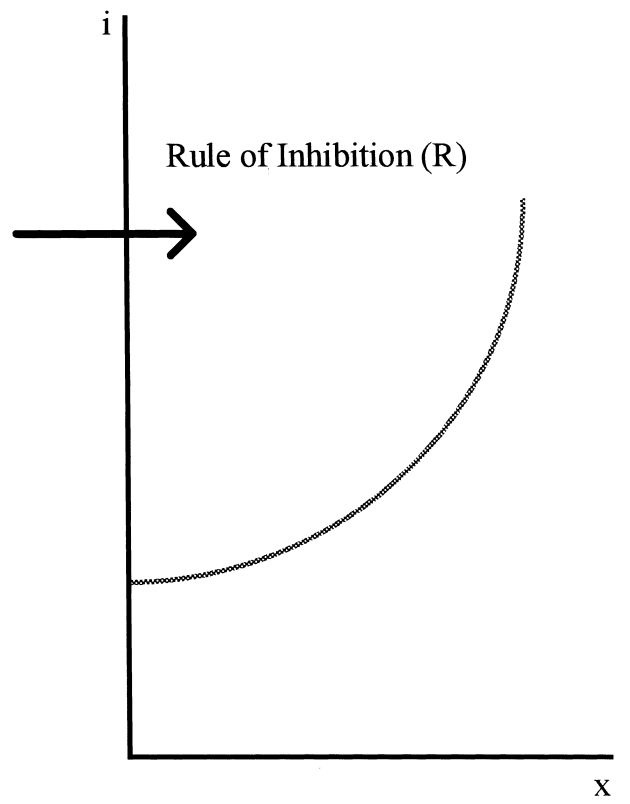

B

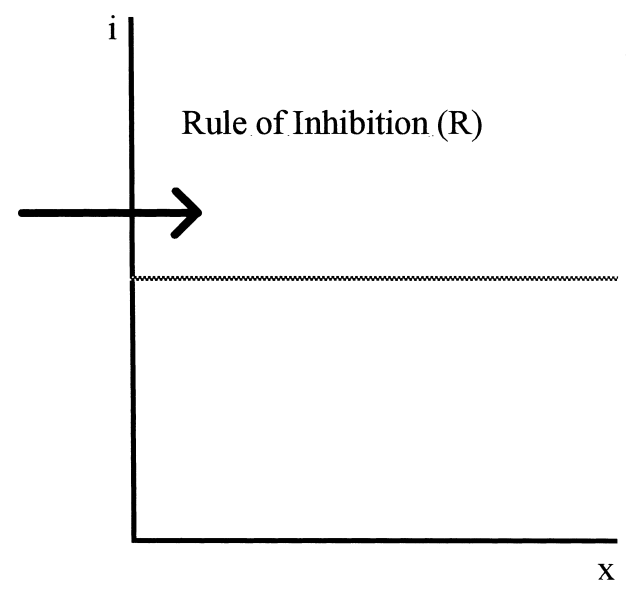

$\mathrm{D}$

FIGURE 7.

Mach's depth sensations as the integral of light sensations.

\section{MACH's "MONOCUlAR" CONCEPTION OF STEREOPSIS}

In addition to this other work, Mach considered advancing what he called a "monocular" theory of stereopsis. It occurred to him that if differences in the illuminance distribution on one retina gave rise to monocular depth sensations, then perhaps it was a similar monocular mechanism that generated stereoscopic depth in a field contributed to by both eyes. Mach remarked, for example, that stereopsis merely depended upon unequal light distributions on 
the retinas (Ratliff, 1966, p. 292). Of course monocular stereoscopy merely depends on lighting differences on one retina.

More to the point, Mach observed that just as a uniformly rising illumination led to a perception of curved relief for one eye, so two uniformly rising illuminations on two retinas gave a sensation of a surface of still greater relief in stereopsis (Ratliff, 1966, p. 290). What he seems to be implying is that use of both eyes merely strengthens effects already seen in the operation of just one eye. Furthermore - and this is a barely concealed attack on the projection theory-Mach claimed that detecting the contours of objects was not necessary for stereoscopic relief. He argued that it was not necessary to discern two shapes on either retina, judge them as similar and then "compute" their disparity. Only the two unequal light distributions themselves were needed: "Each image alone gives the impression of the plastic cylindrical surface referred to above. They appear even more plastic when I superimpose them by crossing my eyes. In this way the stereoscopic images can be constructed without any contours" (Ratliff, 1966, p. 290). (The fact that two light surfaces alone suffice for stereopsis was rediscovered and demonstrated in a more dramatic form by Bela Julesz in 1962, when he introduced the random dot stereogram [see Turner, 1994, pp. 271-272].)

Mach speculated further in print that although depth sensation in stereopsis originally resulted from "the reciprocal action of the two retinas it is possible to develop through the reflex connections of light and depth, depth sensations on the one retina." (Ratliff, 1966, p. 298). Once again the implication was that what both eyes do, one eye can do alone. If so, then the differences in the light distribution in a field contributed by the two eyes could be said to trigger sensations of depth by the same mechanism the monocular depth sensations obeyed, with the other eye introduced merely to further enhance the monocular effects. In a Notebook entry of 1875 he speculated further: "Both eyes together give stereoscopy. One eye can do it with the help of the other. It can be that the monocular is primary. Binocular the secondary thing." 10

Mach also noticed that in the monocular field of vision, moving images and images that shrank or grew triggered sensations of depth" ${ }^{11}$ : "Height and width grows with depth. Difference of height and breadth gives depth." 12

In still another place, he made a more general remark: "Light contrast depth. Space contrast depth." ${ }^{13}$ Mach thus considered differences in spatial distribution (for example, by a moving image) to be differences leading to depth just like changes of illuminance. In fact, from what he says, it seems to me there would have been very little separating a mass of diachronically moving, shrinking and growing light sensations in monocular vision, and two light distributions presented simultaneously in a fused binocular field. Abstractly considered, both would contain nothing but differences in the spatial distribution of light.

10. "Beide Augen zusammen geben Stereoscopisches. Ein Auge kann es mit Hilfe des anderen geben. Es kann aber das Monoculare auch das Primäre sein. Das Binoculare das secondäre.” Notebook dated 20 August 1875 (NL 174/02/07).

11. Mach investigated figures he made out of rods and movable joints called Plateau's wire nets, finding that if he subjected the nets to volume expanding and contracting motions, the visual impression was instead of an object of constant volume undergoing rotation. Perspective reversal occasioned a reversal of the direction of rotation. Differences of the position of the rods occasioned special offsetting sensations of depth in order to maintain the perception of an object (Mach, 1868, pp. 4-5).

12. "Höhe und Breite wächst mit der Tiefe. Differenz von Höhe und Breite gibt Tiefe." Notebook dated 20 August 1875 (NL 174/2/7).

13. "Lichtcontrast Tiefe. Raumcontrast Tiefe." Notebook dated April 1882 (NL 174/2/19). 


\section{STEREOPSIS: THE PHENOMENOLOGICAL MYSTERY}

The perennial mystery of stereopsis is how two separate retinal images fuse into a single three-dimensional object of homogeneous light, length, width, and depth sensation. Mach's views shed some light on how he might have tackled this mystery, had he expanded his observations from the cryptic hints above.

If one imagined, for example, that the visual cortex was similar to a monocular surface with one eye brought to the help of the other, as Mach seemed to think, then the fields contributed by both eyes could be mapped on top of one another onto a flat surface. A row of single images would be mapped on top of one another from the corresponding points, and on noncorresponding points, a set of double images, superimposed flat on top of one another. (Imagine that one was given two sheets of graph paper with images and their coordinates, and that one had to map these images onto a single sheet by superimposing the coordinates.) The key point is that retinal disparities from the two eyes would show up simply as differences of spatial light distribution on a flat surface. This is what I take Mach to mean by a conception of stereoscopy that starts from the behavior of a monocular field.

What would happen, then, if the two Machian mechanisms for monocular stereoscopy worked on this fused surface, the way he claimed they did on a single retina? In Mach's view, length and width were no more fixed than light and could shrink or grow in place. In the example of the Mach Card, he had proposed that light and spatial distribution in monocular vision were all sensed as fluid. By adding or removing depth sensation, an image on the surface could distend in both shape and brightness. It is no leap to imagine that perhaps a disparate mass of light sensations could be made to coalesce by adding and subtracting depth sensation. No intellectual similarity between images would be required if these adjustments were made automatically. Indeed Mach's mechanistic philosophy of mind forbade unconscious inferences or higher cognitive processes in stereopsis.

To some degree, the shrinking of the lengths and changing orientation of the rectangular sections of the Mach Card indicated that spatial changes in the monocular image could be controlled by adding and removing depth sensations. Moreover, since Mach considered a visual object to be an invariant relationship or equation holding between light, depth and length, any of these could suffer alterations in favor of the others. There was certainly room for the idea that the spatial and light distributions of an image could be systematically altered according to a rule by adding and removing depth.

Finally, following Mach's neural inhibition theory, the depth sensations themselves would have undergone mutual inhibition until a single object formed at the mean depth of the entire light distribution. Objects requiring net subtractions of depth sensation would have projected forward while those that required additions would have recessed back from Hering's Kernfläche. Light distributions that were too spatially disparate would have been left as doubled monocular images. The Kernfläche and the double images were already more or less explained by Hering's theory. It was the middle foreground and background of fused images that presented the phenomenological problem and would seem to have required the more complex Machian mechanisms. Such is my preliminary reconstruction of how Machian monocular stereoscopy might have worked.

\section{THE LAW OF INHIBITION FOR DEPTH SENSATIONS}

Mach originally hit upon the idea of expanding his law of lateral inhibition to depth sensations by a study of perspective figures. Now such figures are simply flat lines on paper 


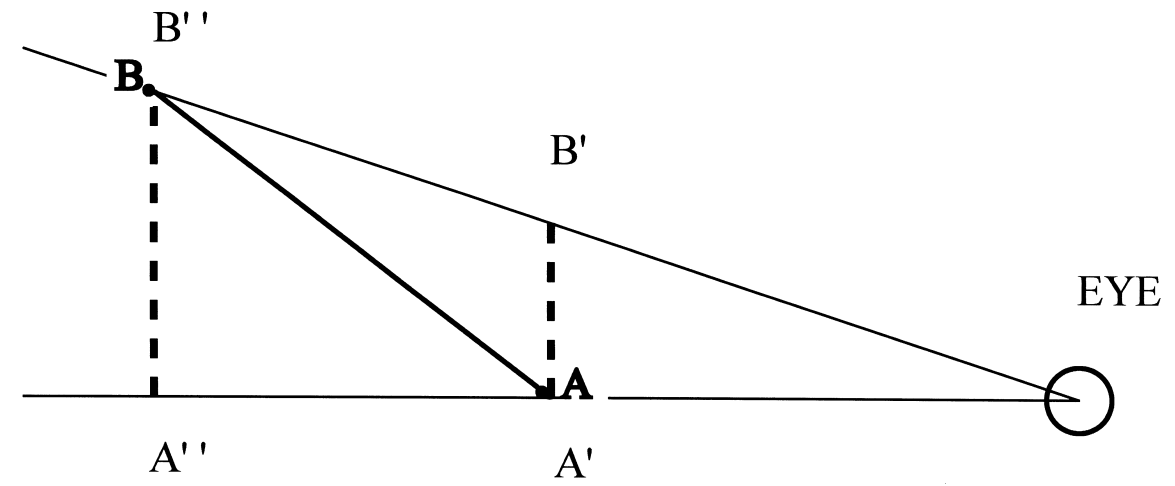

FIGURE 8 .

Preferred depth sensations for a line in space.

arranged at various angles. The task for the eye is to interpret those lines as a cube, a pyramid, or whatever object in space they might be taken to represent. The problem is that a given line drawing always represents an infinite number of spatial objects all consistent with the arrangement of the lines. There is no way to reconstruct an object in space from its perspective image; and yet the eye always manages to reduce its choices to two or three possibilities at the most. This was the fact that intrigued Mach:

The most striking thing for me about these observations is the way the eye is determined in the interpretation of monocular figures. Although for the geometer it would be a completely indeterminate task to seek out the object for a monocular figure, the eye sees only very few forms and positions. Therefore there yet must lie conditions in the eye that further determine it. (Mach, 1868, p. 734)

Mach claimed that, whenever possible, a line image cast on the retina was always seen as if it were cast by a straight line in space, erected in a plane perpendicular to the line of sight, in other words a flat plane seen by an eye staring dead ahead (see Figure 8). Mach said the possibility was always summarily discounted that the image was cast by a curve or by a line inclined in space, such as a crooked flagpole or curved streetlight that was bent into, or away from, the plane of the viewer. Whenever possible, the angle of inclination between a line and the line of sight was always seen as a right angle (Mach, 1868, p. 734). In Figure 8 for example, line BA, tilted out of the plane of vision, would always be seen as $\mathrm{B}^{\prime} \mathrm{A}^{\prime}$ or as $\mathrm{B}^{\prime} \mathrm{A}^{\prime \prime}$ or as any other line parallel to these and consistent with other perceptions. Of course, the empiricist theory could also have explained Mach's rule, because it was overwhelmingly unlikely that a tilted, broken, or crooked line would be seen edge on as a straight line. It was much more likely that straight line images were, not surprisingly, cast by straight lines.

Mach, however, attributed an innate preference of the eye to the principle that "the eye develops a minimum of depth differences" (Mach, 1886/1959, pp. 214-215). In other words, if an observer had to see a line image as an object in depth, he or she would always at least try to attribute a uniform depth to all points, marked off from the flat plane sitting perpendicular to the line of sight-Hering's Kernfläche. If the perception of uniform depth could not be maintained, the next best case for the eye would be for every depth sensation to be a mean of the neighboring depth sensations - the best case being all points at the same or zero depth. 
Mach's principle of stinginess led him to assert that for all monocular figures, the depth attributed to the corresponding spatial object, when consistent with other perceptions, would be the minimum needed to achieve the perception of straight lines at the minimum possible depth meeting at right angles in space, never curves or more complicated arrangements of broken or crooked lines. Thus, although a dodecahedron in space had edges that had to meet at angles greater than $90^{\circ}$, this would be no counterexample to Mach's principle for seeing figures. The image of a dodecahedron could be cast by a very complex arrangement of straight lines and right angles, but assuming such an object would have meant violating the other half of Mach's principle that lines be seen as inclined at minimal depth.

Mach went on to say that drawings consisting of straight lines and right angles already were preferably not seen in perspective at all and tended to flatten out on the paper. In a fascinating section of the Analysis of Sensations (Mach, 1886/1959, pp. 232-233), which would be of interest to comparative art historians, Mach claimed that children instinctively avoided perspective and preferred to draw a table with all of its angles right and the tabletop flat. In fact, given the task of making a two-dimensional picture of a table as realistic as possible, Mach was suggesting that such a drawing was better than classical Renaissance perspective at preserving the properties of angle-openings, shape, and surface area. Mach interpreted Egyptian figure drawing analogously as a highly naturalistic attempt to press as much of the human body into the two- dimensional plane as possible "as plants are pressed in a herbarium."

Seeking a physiological basis for these many observations, Mach claimed his monocular principle for attributing minimum depth to objects in space was due to inhibition among the monocular depth signs of the retina, a clear extension of his Mach Band principle governing light sensations to Hering's theory: "It appears to me that a completely similar law of the reciprocal action of the retinal points, as I have laid it down for the light sensations, also holds for the sensation of form."14

He elaborated in the Analysis of Sensations:

every point of a straight line in space marks the mean of the depth sensations of the neighboring points. Thus the straight line in space gives the mean of the similar space values of the adjacent points; and the assumption forthwith presents itself that the straight line is seen with the least effort. (Mach, 1886/1959, pp. 214-215)

Mach stated his law of illumination as "the illumination of a position on the retina is felt in proportion to its deviation from the mean illuminations of the adjacent positions" (Mach, 1886/1959, pp. 217-218). Mutatis mutandis the law for depth sensations would read: the attributed depth of a point (if not zero) is in proportion to its minimum possible deviation from the mean of the depths of adjacent points.

In sum, returning to Helmholtz's wall problem, inhibition principles would explain why, if a steady rise of depth sensation were triggered by light sensations, this arrangement of depths would fall victim immediately to the eye's inhibiting preference to see such steady rises as flattened into the plane perpendicular to the line of sight. For stereopsis, Mach stated that Hering's Kernfläche (the old horopter) was this flat-as-possible surface (Mach, 1886/ 1959, pp. 223-225).

14. See Note 3. 


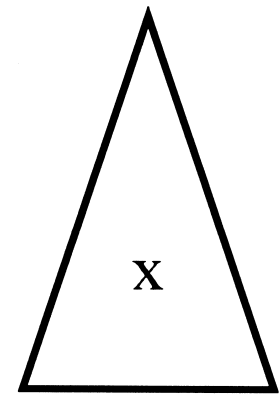

Stare at this triangle

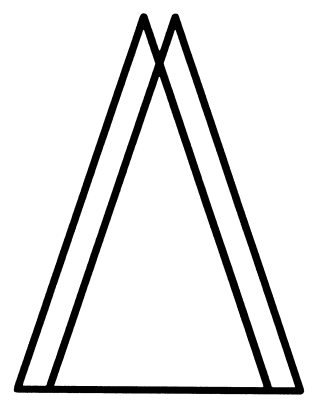

FIGURE 9.

A suggested monocular stereogram. 


\section{EPILOGUE}

Although Mach's observations were systematic, and highly suggestive, he never succeeded in putting these hypotheses together in a crucial experiment, or in enlisting Hering's support. For some reason, Mach did not seek to engineer any tests. Nor, apparently, did other writers contradict him on perspective vision, the connection of light gradients and depth sensation or his adherence to the hypothesis of monocular depth sensations. One immediate question should have been why there are no higher order depth curves generated by curves of greater degree in light intensity, which I believe he may have answered..$^{15}$ A more serious problem for Mach's monocular conception of stereopsis is that his theory (or rather his theory the way I have reconstructed it above) predicts the existence of a "monocular stereogram." By that I mean a double image that can be seen fused and in depth by only one eye, an example of which is Figure 9. By closing one eye and staring with the other at the top triangle marked with an "x," the double triangle below, now in the periphery of the field of vision, should fuse in depth even on a single retina. I have not seen this work convincingly, but it might be an interesting problem for a modern visual scientist to investigate further.

For Mach's part, he remained satisfied with the observations he had made and seems to have been content for his views to be ignored. Unlike Hering, Wundt, and James, Mach was the perennial Aussenseiter who founded no school of psychology; nor did he have designs in that direction. In the Preface to the second edition of the Analyse der Empfindungen (1900), he wrote that he did not intend to update the book by considering new research and letting it "swell out into a bulky volume" (Mach, 1886/1959, p. xxxvii). As time passed, Mach seemed to give the field over to Hering, except for his special research on the sensations of movement. Mach's nativism, though always pronounced, developed further in Hering's direction. For example, species-wide memory and the presence of spatial representation at birth became favored hypotheses of both men.

Meanwhile, Hering's students carried on the fight against Helmholtz without apparently being aware of Mach's work. And, by the turn of the century, Mach's and Hering's physiological approach to sense perception was losing out somewhat to the holist views of Gestalt psychologists, who allowed for cognitive judgment to play a major role-bolstering Helmholtz's idea of unconscious inferences. Similarly, Franz Brentano's students began to frame a psychology of acts in which so-called a priori elements of perception stood out as quasilogical data above psychology, for which a physiological basis was not even sought. But finally, and most devastatingly, the anatomical and physiological expertise was lacking for an accurate observation of the living nervous system and brain - technologies only beginning to develop today. If a physiologist did come across Mach's work earlier, his neglect was not necessarily a sign of ignorance or indifference. At that time there simply may have been no way to use or expand upon Mach's ideas.

15. Mach and Josef Popper had puzzled over the question of why curves had only certain physiological properties for the eye. For example the eye noticed the slope of the curve (the first derivative) and the curvature (which involves the second derivative), but no properties of higher order. Mach's explanation was that the eye only noticed certain of the noticeable deviations of the curve from that of a straight line, or, as he said, the deviation of the line's symmetry to itself. Based on the idea that the resting position is for a line to be situated purely horizontally along the horizon, the slope represents a first deviation from that position and the curvature a second deviation from the first. Higher order deviations from symmetry had no physiological meaning (Mach, 1866, p. 229). 
My thanks to the Deutscher Akademischer Austauschdienst (DAAD) for funding my research and to the Archive of Deutsches Museum and its staff for access to the Ernst Mach Nachlass (including letters, notebooks, and lecture notes) during the summer of 1999. I also thank two anonymous referees whose comments significantly improved this article.

\section{REFERENCES}

Boring, E. (1944). Sensation and perception in the history of experimental psychology. New York: AppletonCentury-Crofts.

Boring, E. (1950). A history of experimental psychology. New York: Appleton-Century- Crofts.

Helmholtz, H. von. (1962). Helmholtz's treatise on physiological optics. New York: Dover. (German original published 1866)

Hering, E. (1865). Beiträge zur Physiologie. Leipzig: Wilhelm Engelmann.

Hering, E. (1977). The theory of binocular vision (B. Bridgeman, Trans.). New York: Plenum Press. (German original published 1868)

Kerkhof, F. (1966). Symposium aus Anlaß des 50. Todestages von Ernst Mach [Symposium on the occasion of the 50th anniversary of Ernst Mach's death]. Freiburg: Ernst Mach Institut.

Mach, E. (1863a). Vorträge über Psychophysik. Oesterreiche Zeitschrift für praktische Heilkunde 9.

Mach, E. (1863b). Zur Theorie des Gehörorgans. Sitzungsberichte der kaiserlichen Akademie der Wissenschaften, mathematische-naturwissenschaftliche Klasse, 48, 283-300.

Mach, E. (1866). Bemerkungen über die Entwicklung der Raumvorstellungen. Fichtes Zeitschrift für Philosophie und philosophische Kritik, 49, 227-232.

Mach, E. (1868). Beobachtungen über monoculare Stereoscopie. Sitzungsberichte der kaiserlichen Akademie, mathematische-naturwissenschaftliche Klasse, Wien, 58, 731-736.

Mach, E. (1875). Grundlinean der Lehre von den Bewegungsempfindungen. Leipzig: Wilhelm Engelmann.

Mach, E. (1959). The analysis of sensations. New York: Dover. (German original published 1886)

Mach, E. (1960). Space and geometry in the light of physiological, psychological and physical inquiry. LaSalle IL: (German original published 1905)

Morrone, M.C., Ross, J., Burr, D.C., \& Owens, R. (1986). Mach bands are phase dependent. Nature, 324(20), 250253.

Ratliff, F. (1966). Mach bands. San Francisco: Holden Day.

Ratliff, F. (1970). On Mach's contribution to the analysis of sensations. In R. S. Cohen, \& R. J. Seeger (Eds.), Ernst Mach: Physicist and philosopher (pp. 23-41). Dordrecht: D. Reidel.

Turner, R. S. (1994). In the eye's mind: Vision and the Helmholtz-Hering controversy. Princeton NJ: Princeton University Press.

Von Békésy, G. (1960). Experiments in hearing. New York: McGraw Hill.

Wundt, W. (1897). Outlines of psychology. New York: E. Steichert. 